\title{
Sobre el final del bagaudismo en Galia e Hispania
}

\author{
Juan Carlos Sánchez león *
}

En ciertas fuentes tardorromanas aparecen mencionadas acciones de violencia, que algunos estudiosos de la historia social bajoimperial han presentado como manifestaciones de bagaudismo en la segunda mitad del siglo $v$ d.C. Se trata aqui de aquilatar si estas violencias tienen características típicamente bagáudicas o si son expresión de otro tipo de desórdenes sociales.

1. Sobre el final del movimiento bagauda en la península lbérica hay diversidad de opiniones. Fue E. A. Thompson quien en 1952 consideró el episodio del latrocinio de Braga en 456 d.C. como una acción constatable del bagaudismo hispano (Hyd., Chron., 179: in conuentu parte Bracarensis, latrocinantum depraedatio perpetratur); para el historiador británico, los bagaudas tarraconenses se habrian extendido hasta Galecia tras las matanzas de bagaudas por parte del visigodo Federico (ex auctoritate romana) en la Tarraconense en 454 d.C. '. Esta interpre-

* UNED, Madrid.

'Thompson, E. A., "Peasant Revolts in Late Roman Gaul and Spain", Past and Present, 2, 1952, 11-23, págs. 16-17; "Hacia el 456 se pueden encontrar bastante lejos en el $\mathrm{NO}$, en las cercanías de Braga, donde fueron lo suficientemente activos como para que encontremos una mención en nuestras pobres crónicas"; el autor mantendria en otro trabajo la existencia de bagaudas en Galecia en 438 sobre la base de Hyd., Chron., 113 (Sueui cum parte plebis Callaeciae, cui adversabantur, pacis iura confirmant), idea que no ha seguido en publicaciones posteriores ("The Visigoths from Frigitern to Euric", Historia, 1963, 105-126, pág. 118, n. 52). CZUTH, B., y SZADECZKY-KARDOSS, S. (“A bagauda mozgalmak Hispaniaban: Die Bagauden-Bewegung in Spanien", Antik Tanulmanyok, 3, 1956, 175-180: $B C O$, c. 3,1958 , pág. 140) también lo creyeron asi: “Estalló en Galecia un nuevo movimiento semejante al de los bagaudas, cuando los godos intentaron arrebatar esta provincia a los suevos amigos de los bagaudas." Sin embargo, CzuTH, B., pasó por alto esta opinión en su repertorio de 1965 (Die Quellen der Geschichte der Bagauden, Szeged), aunque ThOMPSON, E. A., mantenia su postura por esta época ("Bagauden", Lexikon der Alten Welt, 
tación ha sido repetida por la historiografía, incluso después de que el mismo Thompson la corrigiera presentando el latrocinio de Braga como una acción de bandolerismo a gran escala ${ }^{2}$.

Si tenemos en cuenta el momento en que ocurrió esta acción, resulta bastante difícil sostener la hipótesis de la extensión del campo de actuación bagauda en Hispania. En 455 el rey suevo Reckiario había saqueado por dos veces la Tarraconense y una la Cartaginense, que había restituido al Imperio en 452 d.C. Estas acciones provocaron la intervención militar goda en la península y la ruina del reino suevo en 456 d.C. El año anterior los godos habían dado muerte a Reckiario y saqueado Braga ellos mismos, y tras la marcha de Teodorico hacia Mérida se produjo el latrocinio de Braga; los godos también saquearon en Palencia y Astorga ${ }^{3}$.

En este cuadro una acción de bandolerismo común no desentona, amén de la cuestión de que fuera una partida de visigodos los causantes del latrocinio ${ }^{4}$.

Zürich-Sttutgart, 1965, col. 428). Ya en 1932 LAMBERT, A. (“Bagaudes», DHGE, VI, 1932, cols. 192-198), no contaba con el episodio de Braga como fuente de la Bagaudia hispana. En esta misma línea están Sirago, V. A., Galla Placidia e la trasformazione política dell'Occidente, Louvain, 1961, pág. 389; MiNOR, C. E., Brigand, insurrectionist and separatist Movements in the Later Roman Empire, Diss. Univ. of Washington, 1971, Ann Arbor, 1979, pág. 147; Mole, C., "Uno storico del v secolo; il vescovo Idazio", SicGym, 27, 1974, 279351, pág. 344, n. 176; STROHEKER, K. F., «Spanische Senatoren der Spätrömischen und Westgotischen Zeit", en Germanentum und Spätantike, Zürich, 1965, pág. 75, n. 1.

2 THOMPSON, E. A., "The End of Roman Spain, part Il", Notingham Medieval Studies, 21, 1977, 3-31, pág. 30: “En 456 Hidacio ya no los llama bagaudas, tratándose de un episodio de bandolerismo a gran escala." La misma opinión en OrLandis, J., Historia de España. La España visigótica. Madrid, 1977, pág. 37; idem, "Bagaudia Hispánica”, Revista de Historia del Derecho, 2, 1978, 33-47, pág. 37; SAYAS, J. J., "El Bajo Imperio", en Historia de España dir. M. Tuñón de Lara, II, 1. ${ }^{2}$ p., Barcelona, 1981, pág. 150 . Han mantenido la existencia de bagaudas en Braga BARBERO, A.-VIGIL, M., "Sobre los origenes sociales de la Reconquista: Cántabros y vascones desde fines del Imperio romano hasta la invasión mu. sulmana", en Sobre los origenes sociales de la Reconquista, Barcelona, 1974, 11-103, págs. 42, 46 y trabajos posteriores; DE PALOL, A., Castilla la Vieja entre el Imperio Romano y el Reino Visigodo, Valladolid, 1970, págs. 25-26; BLAZQUez, J. M., “El Imperio y las invasiones desde la crisis del siglo III al año 500", en Historia económica y social de España. I: España antigua, dir. L. Vázquez de Parga, Madrid, 1973, 329 ss., pág. 358 y trabajos posteriores; MONTENEGRo, A., Historia Antigua de España, Madrid, UNED, 1977, pág. 496; PASTOR, M., "Consideraciones sobre el carácter social del movimiento bagáudico en Galia e Hispania a fines del Imperio romano", Memorias de Historia Antigua, II, Oviedo, 1978, 205-216, págs. 205-208; SANTOS, "Movimientos sociales en la España del Bajo Imperio", Hispania, 40, 1980, 237-269, pág. 254; MANGAS, J., "La sociedad en la Hispania romana", en Historia de España M. Pidal, dir. Jover Zamora, II, 2, 1982, pág. 67.

3 Hyd., Chron., 170-178, 186.

4 Así, Lambert, A., obra citada, col. 197. Para Tranoy, A. (Hydace. Chronique, París, 1974, I, pág. 48), el episodio de Braga puede relacionarse con movimientos similares a los bagaudas tarraconenses; los causantes del mismo habrian sido priscilianistas, que, en con- 
Por otro lado, algún historiador como Dmitrew ${ }^{5}$ consideró la acción de unos enemigos del emperador Mayoriano en 460 d.C. como obra tardía de bagaudas hispanos; cuando el emperador habia reunido una flota en la bahía de Elche para atacar a los vándalos, éstos, advertidos por unos traidores, destruyeron parte de la flota y frustraron así las intenciones del emperador (Hyd., Chron., 200: Mense Maio, Maiorianus hispanias ingreditur imperator: quo Carthaginensem prouinciam pertendente, aliquantras naues, quas sibi ad transitum aduersum Vandalos praeparabat de litore Carthaginiense, commoniti Vandali per proditores abripiunt. Maiorianus, ita a sua ordinatione frustratus, ad Italiam reuertitur).

No conocemos la identidad precisa de estos traidores cartaginenses a la causa imperial, pero al igual que en el caso de Braga, el cronista Hidacio no utiliza en ningún momento la palabra bagauda para definir los agentes o la acción en sí, cuando ya había calificado como bagáudicos ciertos acontecimientos violentos en la Tarraconense entre 441 y $454 \mathrm{~d}$. C.

Finalmente, el mismo historiador Dmitrew y recientemente $D$. Claude y $\mathrm{H}$. Livermore han interpretado la tiranía de un tal Burdunelus, en 496 d.C. en la Tarraconenese, como la última expresión del movimiento bagauda hispano, según la opinión que Rafael Altamira había mantenido en $1913^{6}$. Esta cuestión no obtuvo gran eco en la historiografia occidental, pero ya en 1955 los filólogos húngaros B. Czúth y S. Szádeczky-Kardoss, en distintos trabajos, dejaron de poner en relación la tiranía de Burdunelo, y la de Pedro diez años después, con el bagaudismo hispano. Los filólogos constataron con acierto que la única fuente que menciona estas acciones de tiranía, la Chronica Caesaraugustana, no las reseña como bagáudicas (ad a. 496: His coss. Burdunelus in Hispania tyrannidem assumit; ad a. 506: His coss. Dertossa a Gotthis ingressa est. Petrus tyrannus interfectus est et caput eius Caesaraugustam deportatum est) ${ }^{7}$.

tacto con desertores del ejército de Teodoríco, habrían adoptado una estrategia armada; recientemente el mismo autor no mantiene esta hipótesis ciertamente difícil de probar (La Galice Romaine, París, 1981, 446).

5 DMitrew, A. D., “Dvizhenie Bagaudov = Die Bewegung der Bagauden», VDI, 1940, 3-4, 101-114, pág. 114.

"Altamira, R., "Spain under the Visigoths", Cambridge Medieval History, II, 1913 $\left(1967^{6}\right), 159$ ss., pág. 161; DMitrew, A. D., obra citada, pág. 114; Claude, C., Geschichte der Visigoten, Stuttgart-Berlín-Koln, 1970 pág. 35; LIVERMORE. The Origins of Spain and Portugal, London, 1971, pág. 130.

${ }_{7}$ CZUTH, B.-SzADECZKY-KARDOSS, “Burdurellus az utolzo bagauda vezèr? = Burdurellus der letzte Bagaudenführer?", Antik-Tanulmanyok, 2, 1955, 113-120=BCO, c. 3, 1957, 150151, pág. 150; CzUTH, B., obra citada, pág. 139; SzadeCZKY-Kardoss, S., “Bagaudae», RE Suppl., XI, 1968, 346-354, col. 353. En la misma línea, Stroheker, K. F., "Spanien in spätromischen Reich (284-475)», AEArq, 45 (1972-1974), 587-605, pág. 600, n. 52. 
Habria que entender las tiranías de Burdunelo y Pedro en el contexto general de la resistencia tarraconense a la conquista visigoda a fines del siglo v d. C. ${ }^{8}$. En 472-3 un ejército godo al mando del "comes" Gauterio entró en Hispania, se apoderó de Pamplona y Zaragoza y ciudades vecinas y aniquiló a la nobleza tarraconense que se había resistido por las armas; otro ejército al mando de Heldefredo y del dux Hispaniarum Vincentius penetró por los pasos orientales de los Pirineos, entró en Tarragona y ocupó las principales ciudades del litoral ${ }^{9}$. La rebelión de Burdunelo tuvo lugar sin duda en el Valle Medio del Ebro, en los alrededores de Zaragoza; como dice Thompson, no se sabe de ninguna otra área peninsular que estuviese amenazada con un asentamiento godo en estas fechas (en 497 d.C. la Chron. Caesaraugust. concreta un asentamiento godo: intra Hispanias sedes acceperunt) ${ }^{10}$. Como ya se ha visto, en esta misma zona la nobleza tarraconense se había resistido a los godos de Gauterio veinte años antes. Es más probable que Burdunelo, cuyo nombre hispano es evidente, articulase en su rebelión los intereses de la nobleza del Valle Medio del Ebro contra el invasor, al igual que

${ }^{8}$ Sobre los visigodos en Hispania véase en general OrLandis, J., Historia de España. La España Visigótica; Thompson, E. A., Los godos en España, Madrid, 1971; King, P. D., Law and society in the visigothic Kingdom, Cambridge, 1972; ClaUdE, D., Adel, Kirche und Königtum im Westgotenreich, Sigmaringen, 1971; Collins, R., España en la Alta Edad Media, Barcelona, 1986; Barbero, A., ViGil. M., La formación del feudalismo en la península Ibérica, Barcelona, 1978; Nelson, C. A. S., Regionalism in visigothic Spain, Univ. of Kansas, Ann Arbor, 1979.

${ }^{9}$ El dominio godo sobre la Tarraconense posiblemente fue legitimado de iure hacia el 475 d.C. con el foedus entre Eurico y el emperador J. Nepote, por el que el Imperio reconocia el dominio visigodo sobre la recientemente ocupada Auvernia a cambio de la devolución de Provenza. Véase BlAzQuez, J. M., "La Hispania del 476", en VV.AA., La caída del Imperio romano de Occidente en el año 476, Cuadernos de la Fundación Pastor, 24, Madrid, 1980, 24 ss., págs. 67 ss.

10 Thompson, E. A., "The End of Roman Spain, part III", Nottingham Medieval Studies, 22, 1978, 3-22, pág. 8; también D'ABADAL, R., "L'establiment dels Visigots a Hispania: Del Regne de Tolosa al Regne de Toledo", en Dels Visigots als Catalans, I, Barcelona, 1969, 27-57, pág. 43, 45.

"Según D'ABadal, R., obra citada, pág. 43, Burdunelo fue jefe de un movimiento popular indígena. Pero según el autor anónimo de la Chronica Caesaraugustana e Isidoro las tiranias de Burduneto y Atanagildo fueron similares, usurpaciones contra el poder legitimo, lo que conviene mejor a una acción de rebelión organizada de la nobleza tarraconense; véase ORLANDIS, J., "En torno a la noción visigoda de tirania". Estudios visigodos, III. El poder real y la sucesión al trono en la monarquia visigoda, Roma-Madrid, 1962, pág. 30. Por otro lado, para Dominguez Monedero, A., Burdunelo sería un jefe militar rebelado al mando de tropas visigodas ("La Chronica Caesaraugustana y la presunta penetración popular visigoda en Hispania", en Los visigodos. Historia y civilización, Murcia, III, 1987, 6168, págs. 64-65). Para Jimenez Garnica, M., "Los primeros establecimientos permanentes de visigodos en Hispania", Hispania, 42, 1978, págs. 499-500, se trataría de un villicus que obligaria a la población visigoda a ponerse bajo su patrocinio, arrebatando así los dominios 
debió ocurrir con la rebelión de Pedro, en este caso representando a la nobleza del litoral tarraconense. Aunque la independencia política de esta provincia habia cesado militarmente con la ocupación visigoda de 472-3, es muy probable que hasta el 494 d.C. sólo existiera dependencia política y administrativa de Tolosa, y que una migración continua de visigodos entre 494 y 497 d.C. amenazara a la nobleza tarraconense ${ }^{12}$.

Últimamente, E. A. Thompson, comparando las rebeliones de Pedro y Burdunelo con la actitud de los tiranos de Britania en el siglo $\vee$ d.C., concluye que lo más probable es que tras la desaparición del poder imperial en Hispania, algunos representantes de la nobleza hispana (o de otros grupos sociales) adquirieran un poder efimero e intentaran organizar defensas locales contra los bárbaros invasores ${ }^{13}$. En este sentido creemos que más que líderes de bagaudas, Burdunelo y Pedro fueron representantes de la nobleza tarraconense ante la conquista goda de fines del siglo $\vee$ d.C.

2. L. Fleuriot, gran estudioso del problema de la emigración bretona en Armónica a fines de la Antigüedad ha recogido la teoría de N. K. Chadwick sobre la influencia bretona en las sublevaciones armoricanas del siglo $\vee$ d.C., dotándola de nuevas evidencias en relación al bagaudismo ${ }^{14}$. Para Fleuriot, los restos de las tropas de los usurpadores Maximus y Constantino III-Constante a fines del siglo IV y comienzos del $\checkmark$ d.C. pudieron haber constituido el elemento más o menos organizado de los bagaudas (Chadwick), además de la posible alianza entre bagaudas galos y Constantino III que aparece mencionada en el Liber Ambaziae. Otras fuentes, según el mismo autor, sobre la posible colaboración de los bretones con los bagaudas a fines del siglo $\vee$ d.C. son las "Vitae» de $S$. Melar y de Melanius, en las que se hace referencia a autoridades

\footnotetext{
al rey. Según ORlandis, J. (Zaragoza visigótica, Zaragoza, 1968, págs. 15-16, n. 23), Burdunelo era un prócer hispano, cosa que ya había sugerido Garcia Gallo, A., al caracterizarlo como un jefe territorial que buscaba conservar el poder ("Consideración critica de los estudios sobre la legislación y las costumbres visigodas", Anuario de Historia del Derecho Español, 44, 1974, págs. 426-427).

${ }^{12}$ Según D'ABADAL, R., obra citada, pág. 43, los asentamientos godos de la meseta superior comenzaron en 462 d.C. y entre 494-497 se produjo una verdadera ocupación de la región de Zaragoza, atestiguada en la Crónica Cesaraugustana. En la misma línea ORLandis, J., Historia de España. La España visigótica, pags. 76-81; en contra, Garcia MoRENO, L., "Mérida y el reino visigodo de Tolosa (418-507)". Homenaje a Sáenz de Buruaga, Madrid, 1982 , págs. $227 \cdot 240$.

${ }_{13}$ Thompson, E. A., "The End of Roman Spain, part IIl”, pág. 8; idem, “Britannia A.D. 406-410", Britannia, 8, 1977, 303-318, págs. 316-317.

${ }_{14}$ FLEURIOT, L., Les Origines de la Bretagne. L'emigration, París, 1982², págs. 130-133; CHadWICK, N. K., Early Brittany, Cardiff, 1969, 144 ss.
} 
armoricanas de algunas ciudades que han llevado a cabo acciones de violencia en la segunda mitad del siglo $v$ d.C.

En la Vita sancti Meloris martyris, 1 , se menciona la desolación infligida por los frisones y el "dux" de Corseul en Armórica occidental; este dux habría luchado contra los bagaudas, que estarian más o menos apoyados por los federados bretones, al haber éstos interpretado libremente la misión que se les había confiado de defender el pais contra sajones y frisones, según Fleuriot ${ }^{15}$.

Por otro lado, en la Vita Melanii, 5 (obispo de Rennes que tuvo un papel mediador entre armoricanos y francos a fines del siglo $\vee$ d.C.), se relata la expedición del "rey» de Vannes Eusebius contra los habitantes de Comblessac, en el departamento de lle-et-Vilaine. En opinión de Fleuriot, esta campaña estaria dirigida contra bagaudas, quizá apoyados por bretones, aunque éstos están prácticamente ausentes de esta región a fines del siglo $\vee$ d. C. ${ }^{16}$.

Parece razonable admitir la existencia de una migración bretona precoz en Armórica durante época romana; es posible que algunos elementos militares bretones formaran parte de los bagaudas y que hubiera una cierta alianza entre ellos ${ }^{17}$. Ahora bien, parece que la primera migración en masa del pueblo bretón ocurrió a mediados del siglo $\vee$ d.C. (Gildas), por lo que sólo se podría admitir una participación y/o alianza relativas

15 F. Plaine ed., Analecta Bollandiana, 5, págs. 165-175: Quidam nobilis apud transmarinos exstitit, cui cognomen erat Lex vel Regula; vir quidem genere regius, terra, familiis, opibus admodum opulentus... Is post desolationem Frixonum et Corsoldi ducis, nostram adiens desertam Cornugalliam, (parata) classe mare cum maximo apparatu transmisit, regnum accepit, habitavit, excoluit. Sobre S. Melar, Doble, CH., Saints of Cornwall, 3 p., Oxford, 1960-1965, 20 ss.; LOT, F., Mélanges d'Historie Bretonne, Paris, 1907, pág. 123, n. 2. En opinión de Fleuriot, Corsoldi ducis, correctamente comprendido al principio como "dux" de Corseul, ha sido mal interpretado como "dux" Corseul.

${ }^{16}$ B. Krusk ed., MGH Scr. rer. Merov., 3, Hannoverae, 1896, 370-376: (rec. 1) Denique Eusebius rex veniens in Venonicum cum suo exercitu, pertendit usque ad Cambliciagum villam, et ibu multos oculos hominum erui iussit et manus abscidi; (rec. 2) Denique Eusebius rex crudelissimus veniens de Venonica civitate cum suo exercitu, pertendit usque ad Cambliciacum villam, ubi castrum situm est que vocatur Marciacus super rivulum Ava nomine. Hinc veniens, multos oculos hominum erui iussit et manus abscidi.

17 De hecho, los bretones presentaron actitudes de bandolerismo en la segunda mitad del siglo $\vee$ d.C. y siglos posteriores en la misma zona que dominaron los bagaudas; en 470 d.C. los bretones ayudaron a huir a los esclavos de un gran propietario (APOLINAR, Sidonio, Epist., III, 9); en 491 d.C. ejercen el bandolerismo entre Tours y Orleáns, manteniendo el "oppidum" de Blois contra los francos (Crónica de Anjou, ed. Marchegay, pág. 23); en la Alta Edad Media hubo razzias continuas de los bretones de Vannetais contra el poder franco (LOTH, J., L'emigration bretone du $5^{\circ}$ au $7^{\circ}$ siècle de nôtre ère, Rennes, 1883, págs. 171 ss.). 
de elementos bretones en el bagaudismo armoricano, aunque no hay fuentes explicitas que corroboren esta hipótesis; el presunto apoyo de los bretones a presuntos bagaudas en Armórica a fines del siglo $\vee$ d.C. contra autoridades ciudadanas no deja de ser una especulación de Fleuriot a partir de acciones que quizá haya que entender como expresiones de la resistencia local de los armoricanos contra los invasores de la región (bretones [?], sajones, francos).

En definitiva, los textos que algunos estudiosos han puesto en relación con bagaudismo tardio no mencionan nunca la palabra bagauda para caracterizar los agentes o las acciones de violencia que describen, ni contienen la suficiente base crítica como para ser considerados como fuentes de la historia de los bagaudas. Las últimas revueltas bagáudicas constatadas en Armórica y Tarraconense debieron ser reprimidas con efectividad por los alanos y visigodos leales al Imperio entre 448-451 y 454 , respectivamente. Desde entonces no volvemos a tener noticias fiables sobre la existencia de bagaudismo en Occidente. 